\title{
A Brief Parametric Analysis of Catastrophic or Disastrous Hurricanes That Have Hit the Florida Keys between 1900 and 2000
}

\author{
J. M. D'Andrea \\ University of South Florida Sarasota, Manatee, Sarasota Campus, Sarasota, Florida, USA \\ Email: jdandrea@mail.usf.edu
}

How to cite this paper: D'Andrea, J.M. (2018) A Brief Parametric Analysis of Catastrophic or Disastrous Hurricanes That Have Hit the Florida Keys between 1900 and 2000. American Journal of Computational Mathematics, 8, 1-6.

https://doi.org/10.4236/ajcm.2018.81001

Received: June 19, 2017

Accepted: February 20, 2018

Published: February 23, 2018

Copyright $\odot 2018$ by author and Scientific Research Publishing Inc. This work is licensed under the Creative Commons Attribution International License (CC BY 4.0).

http://creativecommons.org/licenses/by/4.0/

\begin{abstract}
The most intense and catastrophic hurricanes on record to hit the Florida Keys during 1900 to 1950 were in 1919, and 1935. From 1950 to 2000, the most intense hurricanes to hit or affect the Florida Keys were in 1960, 1965, and 1992. In this paper, we will present a brief parametric analysis of the hurricanes that have hit the Florida Keys in the last 100 years. This analysis will include the descriptive statistics, best fit probability distribution of the latitude of the catastrophic hurricanes and a confidence interval that detects the average latitude of hurricanes (category 3 or higher) which have hit the Florida Keys in the last 100 years.
\end{abstract}

\section{Keywords}

Florida Keys, Hurricanes, Parametric Analysis, Statistics, Probability

Distributions, Latitude, Confidence Intervals

\section{Introduction}

The research statement/question that will be addressed in this paper is: 1) Determine the best fit probability distribution of the latitude of hurricanes (category 3 or higher) that have hit the Florida Keys in the last 100 years. 2) Determine the confidence interval that detects the average latitude of hurricanes (category 3 or higher) which have hit the Florida Keys in the last 100 years.

Before we begin the analysis of addressing our research statements, let us give a brief history of the catastrophic or disastrous hurricanes that have hit the Florida Keys from 1900-2000. In 1919, Key West, FL was hit by the most powerful hurricane in its history, making it number six on the top ten Deadliest United States Hurricanes list [1]. It was the only hurricane to form in the Atlantic that 
year [1]. The storm killed more than 800 people before it was done, with the exact number not known. In 1935 on Labor Day, the ninth most intense hurricane to strike the United States hit the Florida Keys, which killed approximately 408 people [1]. In 1960, Hurricane Donna (nicknamed Deadly Donna) first made landfall on Conch Key, or near Marathon FL. In Tea table Key, the bridge connecting US 1 to the other side of Marathon was destroyed [1]. On September 8th 1965, Hurricane Betsy (Category 3) made landfall in Tavernier, FL [1]. This storm became the first billion-dollar hurricane, causing 1.2 billion in damage [1]. On August 24th 1992, Hurricane Andrew (Category 5) made landfall on Elliott Key and later in Homestead, FL [2]. A total of 65 deaths attributed to the storm while around 150,000 to 250,000 people in South Florida were left homeless [2]. Andrew was the first storm that meteorologists were able to see on Doppler Radar in 1992 [2].

To address the research statements, we will use parametric analysis methods. Parametric statistics is a branch of statistics which assumes that the data have come from a type of probability distribution and makes inferences about the parameters of the distribution [3].

In this paper, we are only interested in the catastrophic or disastrous hurricanes that have hit the Florida Keys in the last 100 years (1900-2000) to see if we can provide some information about the starting location(s) of when the next catastrophic or disastrous hurricane will occur. In Table 1, the descriptive statistics for the variable latitude is shown, of the 100 years of catastrophic or disastrous hurricanes that have hit the Florida Keys. In Table 2, the descriptive statistics for the variable longitude is shown, of the 100 years of catastrophic or disastrous hurricanes that have hit the Florida Keys.

\section{Descriptive Statistics}

From the tables above, we can see that there are 111 pieces of data for each variable. Notice that the longitude's range (74.8) is a little more than half of the latitude's range (41). This means that the catastrophic or disastrous storms to hit

Table 1. Descriptive Statistics for Latitude of catastrophic or disastrous hurricanes that have hit the Florida Keys between 1900 \& 2000.

\begin{tabular}{cccc}
\hline Statistic & Value & Percentile & Value \\
\hline Sample Size & 111 & Min & 16 \\
Range & 41 & $5 \%$ & 17.8 \\
Mean & 28.211 & $10 \%$ & 20.04 \\
Variance & 87.244 & $25 \%(\mathrm{Q} 1)$ & 23.7 \\
Standard Deviation & 9.3405 & $50 \%($ Median$)$ & 24.9 \\
Coefficient of Variation & 0.3311 & $75 \%(\mathrm{Q} 3)$ & 29.1 \\
Std. Error & 0.88656 & $90 \%$ & 43.98 \\
Skewness & 1.7062 & $95 \%$ & 52.8 \\
Excess Kurtosis & 2.3516 & Max & 57
\end{tabular}


Table 2. Descriptive Statistics for Longitude of Catastrophic or Disastrous Hurricanes that have hit the Florida Keys between 1900 \& 2000.

\begin{tabular}{cccc}
\hline Statistic & Value & Percentile & Value \\
\hline Sample Size & 111 & Min & -106 \\
Range & 74.8 & $5 \%$ & -100.1 \\
Mean & -74.991 & $10 \%$ & -94.44 \\
Variance & 280.47 & $25 \%(\mathrm{Q} 1)$ & -83.4 \\
Standard Deviation & 16.747 & $50 \%($ Median$)$ & -77.3 \\
Coefficient of Variation & -0.22332 & $75 \%(\mathrm{Q} 3)$ & -70.4 \\
Std. Error & 1.5896 & $90 \%$ & -46.0 \\
Skewness & 1.0213 & $95 \%$ & -33.48 \\
Excess Kurtosis & 1.2258 & Max & -31.2 \\
\hline
\end{tabular}

the Florida Keys between 1900 \& 2000 has a much wider East-West range versus North-South range. This can be seen in Figure 1.

The mean of longitude is -74.991 , which is negative. Whereas the mean of latitude is 28.211 and is positive. The standard deviation of longitude is 16.747, which is almost twice that of latitude's standard deviation, which 9.3405 is. Longitude's variance is 280.47 and latitude's variance is more than half of longitude's variance with a value of 87.244 . This means between $1900 \& 2000$ of the catastrophic or disastrous hurricanes that hit the Florida Keys, there seems to be much more variability in longitude values versus latitude values. Since the longitude values of these hurricanes have more variability versus the latitude values, then we will use parametric analysis to determine the correct probability distribution for the latitude of these hurricanes.

If the correct probability distribution function is found, then we may be able depict when the next catastrophic or disastrous hurricane may hit the Florida Keys. For every subset of our data set, they will be compared against 65 continuous distributions, where the goodness-of-fit tests (Anderson-Darling, Kolmogorov-Smirnov, and Chi-Square) will be performed [4].

Using the above statistical methods (the Anderson-Darling, KolmogorovSmirnov, and the Chi-Square Goodness-of-Fit-Tests), the top 3 best fit distributions for Latitude of Catastrophic or Disastrous Hurricanes that have hit the Florida Keys between 1900 \& 2000 are listed in Table 3.

The best fit probability distribution for latitude is the Burr distribution. The Burr distribution is considered continuous probability distribution for a nonnegative random variable [5]. "It is also known as the Singh-Maddala distribution and is one of a number of different distributions sometimes called the 'generalized log-logistic distribution' [5]". The Burr distribution is denoted as:

$$
f(x)=\frac{\alpha k\left(\frac{x-\gamma}{\beta}\right)^{\alpha-1}}{\beta\left(1+\left(\frac{x-\gamma}{\beta}\right)^{\alpha}\right)^{k+1}} \text {, where } k>0, k \text { is a continuous shape parameter, }
$$




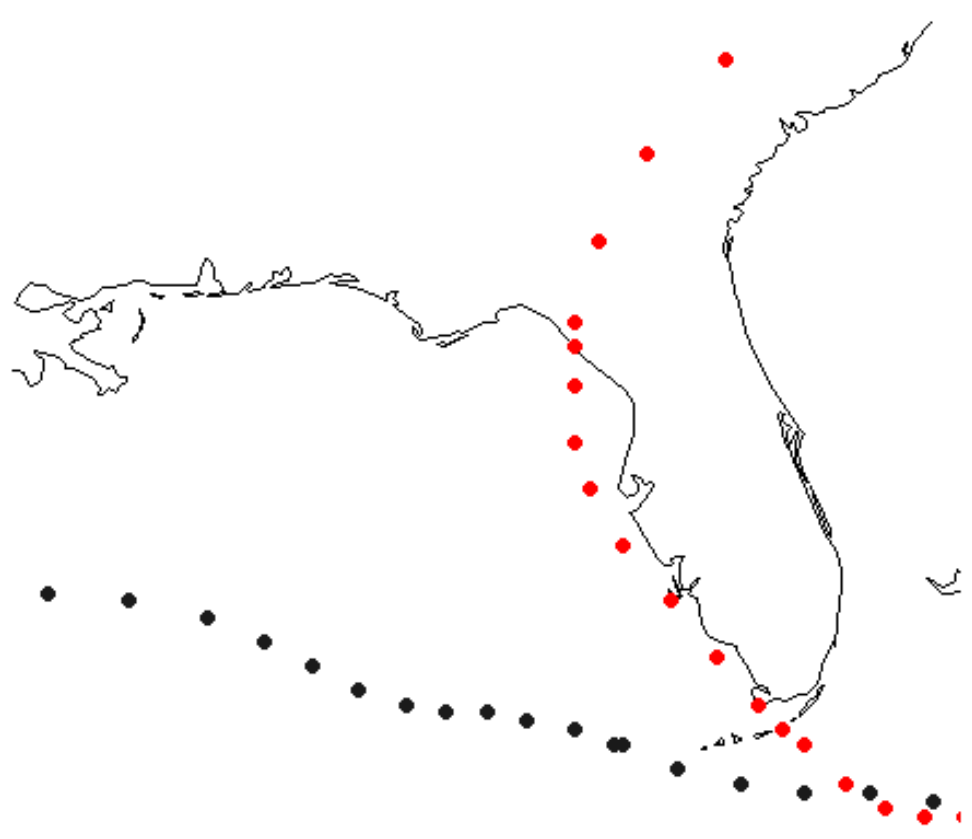

Figure 1. Wider East-West range of catastrophic or disastrous storms to hit the Florida Keys between 1900 \& 2000.

Table 3. Goodness-of-Fit-Tests for the top 3 best fit distributions for Latitude of catastrophic or disastrous hurricanes that have hit the Florida Keys between 1900 \& 2000.

\begin{tabular}{ccccccc}
\hline & \multicolumn{2}{c}{ Anderson-Darling } & \multicolumn{2}{c}{ Kolmogorov-Smirnov } & \multicolumn{2}{c}{ Chi-Square } \\
\hline Distribution & Statistic & Rank & Statistic & Rank & Statistic & Rank \\
Burr & 2.1098 & 2 & 0.10895 & 1 & 35.354 & 7 \\
Burr (4P) & 2.0578 & 1 & 0.11083 & 2 & 31.209 & 6 \\
Dagum & 2.7117 & 5 & 0.12852 & 3 & 39.667 & 13 \\
\hline
\end{tabular}

$\alpha>0, \alpha$ is a continuous shape parameter, $\beta>0, \beta$ is a continuous scale parameter, and $\gamma$ is a continuous location parameter. The Burr distribution is shown in Figure 2.

Next, we will address our second research question: Determine the confidence interval that detects the average latitude of hurricanes (category 3 or higher) that have hit the Florida Keys in the last 100 years. We will estimate the average latitude of catastrophic or disastrous hurricanes that have hit the Florida Keys between $1900 \& 2000$ using confidence intervals.

Using statistical methods to find the Maximum Likelihood Estimates (MLE's), we obtain the following parameter estimates $\hat{k}=0.34244, \hat{\alpha}=12.529$, $\hat{\beta}=22.229, \hat{\gamma}=0$. The cumulative distribution is given as:

$$
F(x)=1-\left(1+\left(\frac{x-\gamma}{\beta}\right)^{\alpha}\right)^{-k}
$$

In using this cumulative distribution formula, we can solve for a $95 \%$ confidence interval by setting the cumulative distribution equal to 0.025 and 0.975 . 


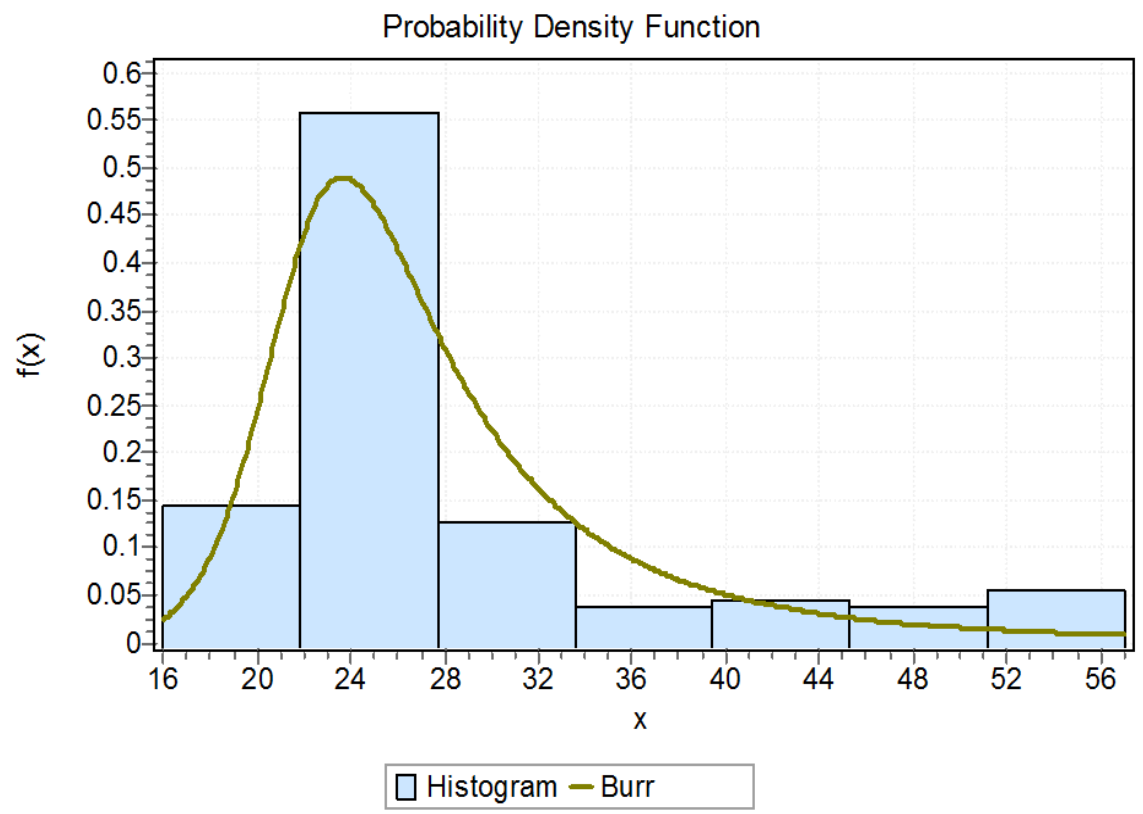

Figure 2. The Burr Distribution for Latitude of Catastrophic or Disastrous Hurricanes that have hit the Florida Keys between $1900 \& 2000$.

Substituting our parameter estimates into the cumulative distribution above, we have the following: $F(x)=1-\left(1+\left(\frac{x-0}{22.229}\right)^{12.529}\right)^{-0.34244}$.

When we solve these equations for the variable $x$ when $F(x)=0.025$ and $F(x)=0.975$ gives us a $95 \%$ confidence interval of $(1.12,29.71)$, thus we are 95\% confident that the true mean Latitude of Catastrophic or Disastrous Hurricanes that have hit the Florida Keys between 1900 \& 2000 is between 1.12 and 29.71.

\section{Conclusion}

In studying the hurricanes that have been catastrophic or disastrous in the last 100 years which hit the Florida Keys, we have found that the best fit probability distribution for the latitude was the Burr distribution. By finding this best fit probability distribution for the latitude, we can better understand what the probability distribution may be for future catastrophic or disastrous hurricanes that hit the Florida Keys. The starting points of these hurricanes that have hit the Florida Keys, usually occur around the same terminal positions. The maximum likelihood estimates of the found probability distribution can further be investigated to find what the shape of future catastrophic or disastrous hurricanes that hit the Florida Keys are. We also found the average latitude of catastrophic or disastrous hurricanes that have hit the Florida Keys between 1900 \& 2000 is between 1.12 and 29.71. Thus, if the starting location of catastrophic or disastrous hurricanes is known, then the Florida Keys residents will better prepare for these storms. 


\section{Dedication}

To my conch family: Jackie Roberts, Michelle Chapman, George Roberts, Mark Raymond, Brian Roberts, Kevin Roberts, James Raymond, Kayleigh Raymond and Faye Mulcahy (R.I.P. Gram).

\section{References}

[1] Parker, P. (2014) Worst Hurricanes to Hit Florida in the Past Century. http://pparker.org/hurricanes/hurricane_history.htm

[2] Machos, G. (2014) The Story of the Power and Fury of Hurricane Andrew. http://www.hurricaneville.com/andrew.html

[3] Cox, D.R. (2006) Principles of Statistical Inference. Cambridge University Press, Cambridge. https://doi.org/10.1017/CBO9780511813559

[4] Wooten, R.D. and D’Andrea, J. (2016) Modeling Hurricanes Using Principle Component Analysis in Conjunction with Non-Response Analysis. arXiv:1512.05307

[5] Singh, S. and Maddala, G. (1976) A Function for the Size Distribution of Incomes. Econometrica, 44, 963-970. https://doi.org/10.2307/1911538 